\title{
Effects of waterlogging on the soil structure of some Italian soils in relation to the GAEC cross-compliance standard Maintenance of farm channel networks and field convexity
}

\author{
Paolo Bazzoffi, ${ }^{1}$ Salvatore Nieddu² \\ ${ }^{1}$ Council for Research and Experimentation in Agriculture, CRA-ABP Research Centre for \\ Agrobiology and Pedology, Florence; ${ }^{2}$ Cagliari University, PhD student on Soil conservation, \\ environmental vulnerability and hydrogeological protection, Cagliari, Italy
}

\begin{abstract}
The aim of this work is to assess the effectiveness of the cross-compliance standard Maintenance of farm channel networks and field convexity with respect to the environmental objective to maintain soil structure through appropriate measures indicated in Annex IV of REG. EC 1782/03. This GAEC standard concerns arable land and obliges the farmer to maintain the farm channel network and the convex shape of fields with a view to the management and preservation of temporary drainage ditches and permanent channels along the edges of the fields, in order to ensure their efficacy and function in draining away water. Experiments have confirmed that maintaining the farm channel networks and giving fields a convex shape has a positive effect in predisposing the soil to ideal conditions for the preservation of its structure. In particular, we have used the data of a newly conducted laboratory study on the effects of the duration of waterlogging on the stability of soil structure, as well as the results of several studies carried out in the past with the following goals: i) assessment of the effects of soil moisture various levels on the stability of the structure; ii) assessment of the effects of several wetting and drying cycles on aggregate stability; iii) determination of aggregate stability under the influence of freezing and thawing
\end{abstract}

Correspondence: Paolo Bazzoffi, CRA-ABP Agricultural Research Council, Agrobiology and Pedology Research Centre, p.zza M. D'Azeglio 30, 50121 Firenze, Italy. Tel. +39.055 .2491228 - Fax: +39.055 .241485 .

E-mail: paolo.bazzoffi@entecra.it

Key words: cross compliance, farm channels, field convexity, freeze/thaw cycles, GEAC Standard, structural stability, waterlogging, wetting/drying cycles.

Acknowledgment: the authors deeply thank Mr. Andrea Rocchini, technician of the CRA-ABP, and Mr. Alessandro Agnelli for their contribution to soil analyses.

Received for publication: 24 March 2011.

Accepted for publication: 11 April 2011.

(c) Copyright P. Bazzoffi and S. Nieddu, 2011

Under no circumstances figures can be used without prior written consent of the copyright owner.

Licensee PAGEPress, Italy

Italian Journal of Agronomy 2011; 6(s1):e9

doi:10.4081/ija.2011.6.s1.e9

This work is licensed under a Creative Commons Attribution NonCommercial 3.0 License (CC BY-NC 3.0). under different soil moisture conditions; iv) determination of aggregate stability with an increasing number of freeze/thaw cycles $(0,1,3,5,11$ cycles) at field capacity moisture. The tests during which the soil was subjected to freezing and thawing were carried out taking into account the fact that during winter waterlogged soil may freeze, leading to a structure breakdown, due to the expansion of water into the pores during the freezing phase. In general, the results showed that in soils that are sandy and rich in rock fragments, rapid moisture penetration leads to significant disaggregation phenomena compared with soils with higher silt and clay contents. The results also showed that the least extensive disaggregation of the structure occurred with three wetting/drying cycles. This behaviour was more obvious in soils with a greater silt and clay content compared with sandy loam soils. After the third wetting/drying cycle, disaggregation increased with the cycles number increasing. In particular for moisture contents of 50\%, this test confirms that maintaining the farm channels efficacy has a beneficial effect on soil structure, as good draining of water, which is ensured by well-functioning ditches, prevents waterlogging and fights the dispersion of clay and silt (when the soil is dry, these two components form a surface crust that disturbs the water and gas exchange as well as plant growth). Disaggregation due to freezing and thawing is linked very closely to the matrix potential (and hence to the moisture) of the aggregates before treatment. In general it can be said that a water content between saturation and field capacity predisposes the soils to a much higher level of disaggregation compared to soil that is air-dry or at the wilting point. The tests that examined the effect of an increasing number of freeze/thaw cycles showed a logarithmic degradation of structural stability in relation to the number of cycles. However, most of the disaggregation occurred after three freeze/thaw cycles. This experiment showed that only few freeze/thaw cycles are necessary to cause a significant structural degradation of soils with high water content and with a texture ranging from loamy to clayey. The results of the studies allow us to deduce that the Standard is efficient in contributing to the preservation of the soil structure. In fact, maintaining the water drainage network in efficient conditions and giving the fields a convex shape are elements that contribute to the removal of excess water, which results in a decrease of both of the possibility of the dispersal of silt+clay microaggregates and of the risk of structural damages due to freezing and thawing.

\section{Introduction}

\section{Legislation and aim of the study}

GAECs (Standards of Good Agricultural and Environmental Condition) is part of the requirements under cross compliance and apply to anyone who receives payments under the Single Payment Scheme. GAECs set requirements for farmers in respect of soils, as 
well as maintaining a range of habitat and landscape features, which are characteristic of the Italian countryside.

The standard Maintenance of farm channel networks and field convexity concerns the environmental objective to maintain soil structure through appropriate measures indicated in Annex IV of REG. EC 1782/03. This standard was introduced under Rule 3.1 by successive Mipaaf $^{1}$ decrees on cross compliance from mid-2004 (Decree 1787/2004 et seq.) until the end of 2009. The Mipaaf Decree of December 2009, issued following the CAP Health Check ${ }^{2}$, kept this standard (Standard 1.1c) as part of Norm 1 Soil protection measures. The standard was made obligatory for all arable surfaces and requires farmers to maintain the farm channel network and the convex shape of fields in order to ensure their efficacy and function in draining water away.

The cause-effect link between structural stability and the maintenance of the systems for draining water from the fields was highlighted by the description of the standard in the 2007 Mipaaf decree on cross compliance, where it was specified that cross compliance conditions can be considered fulfilled even in the presence of waterlogging and ponding water if the farmer maintained the field channel network in good working condition. This means that the standard's goal is to mitigate the damaging effect of waterlogging on the soil structure. In particular, the Standard applies to fields in the plains, where waterlogging frequently occurs in winter and sometimes also at other times of the year as an effect of irrigation. In Italy, fields in the plains represent about $30 \%$ of the 12.7 million hectares of arable land. Hence, based on an area of this size, the environmental effects of the Standard concern a large part of the national territory. The Standard is clearly aimed at the maintenance of the classical Italian Land set-up systems for soil and water conservation $^{3}$ in the plains which, as stated by Landi (2004): ...essentially serve to remove excess water in order to make soil healthy, facilitate root growth and thus increase production. Today, the most widely used land setting method in the Italian plains is the one called alla Ferrarese (as it has its origins in the area around Ferrara), with a convex surface profile along the field's entire length (Figure 1). The original scheme of the alla Ferrarese method provided for fields with a width of $40 \mathrm{~m}$ and a length of $200 \mathrm{~m}$ and with ditches along the long sides. This system has since been modified repeatedly with respect to field size, size of the drainage channels and set-up of the convex profile. Based on the regulatory references and considering the importance of this cross-compliance standard, it was decided to provide a first agronomic assessment of its efficacy in preserving soil structure. There have not been any specific studies in Italy to assess the effect of the maintenance of a farm's channel network on the deterioration of the soil structure. Since the purpose of the application of the crosscompliance standard is to prevent the submersion of the soil for long periods, it has become necessary to assess whether the removal of water has a favourable effect on the preservation of the soil structure.

In this study carried out in the context of the EFFICOND ${ }^{4}$ project, the

${ }^{1}$ Ministry of Agricultural, Food and Forestry Policies.

${ }^{2}$ On 20 November 2008 the EU agriculture ministers reached a political agreement on the Health Check of the Common Agricultural Policy (CAP). The Health check introduced a number of changes to the EU rules for the Single Payment Scheme (SPS) and other direct aid schemes.

${ }^{3}$ Land set-up systems for soil and water conservation: Systems of surface setting of fields aimed to control runoff, stop soil erosion and landslides, avoid waterlogging, assure infiltration and optimize cultivation (classified in two main groups: flat-land and hilly Agrarian hydraulic land settings, in Italian: Sistemazioni idraulico agrarie).

${ }^{4}$ EFFICOND (EFF $=$ Effectiveness of environmental standards, COND = Cross compliance) is a CRA (Agricultural Research Council) project started in 2009 to meet the specific need of NRN (National Rural Network) to monitor and evaluate the effectiveness of environmental protection actions mandated by the CAP to national agricultural policy and implemented by the Regional Rural Development Plans (RDP). The main project objectives are the evaluation of GAEC standards implemented under cross compliance and the development of agri-environmental indicators for nation-wide scenario analysis. The EFFICOND project involves 10 operational units with experimental fields located throughout the country.

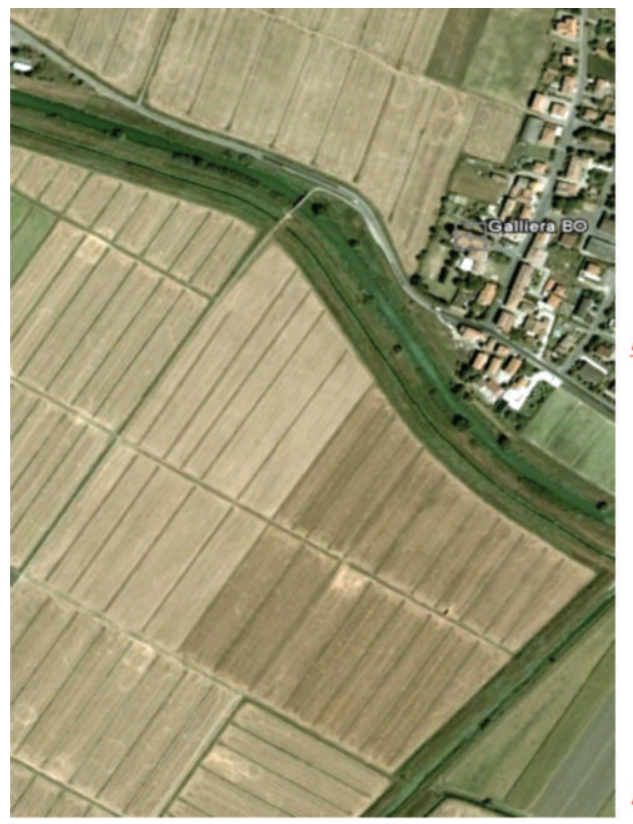

A

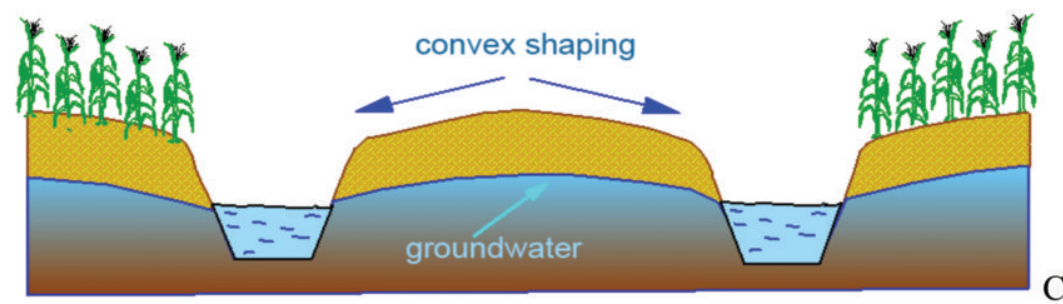

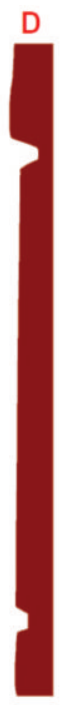

C
Figure 1. An example of a modern system in the plains according to the alla Ferrarese scheme; A) aerial view; B) schematic drawing; C) the convex shaping is an element that contribute to the removal of excess water and predispose the soil to the rapid achievement of a water content below the saturation. 
efficacy of the temporary drainage ditches was assessed; several case studies are presented that investigated the effects of waterlogging on the degradation of soil aggregates and the effects of wetting/drying and freeze/thaw cycles, which are typical phenomena of the Italian plains (Figures 2 and 3). In winter, the latter are subject to an alternation of excessively wet periods and dryer periods, with temperatures that alternate between above and below $0^{\circ} \mathrm{C}$.

In particular, a test regarding the effects of waterlogging on structural stability was carried out to check whether there is a graduation of damages based on the duration of waterlogging, in order to provide sug- gestions regarding the possibility to adapt the sanctions to be applied to farmers based on a severity verification index if infringements of the standard are observed. In this context it should be remembered that in case of the infringement of the GAEC standard Maintenance of farm channel networks and field convexity, the recognition of three verification indexes has been mandatory under AGEA rules since December 2009 as follows: i) extent (based on the area affected by the violation); ii) severity (based on the level of inefficiency of the drainage network); iii) duration (the level of this indicator is calculated based on the assessment of the permanence of the damages).
A

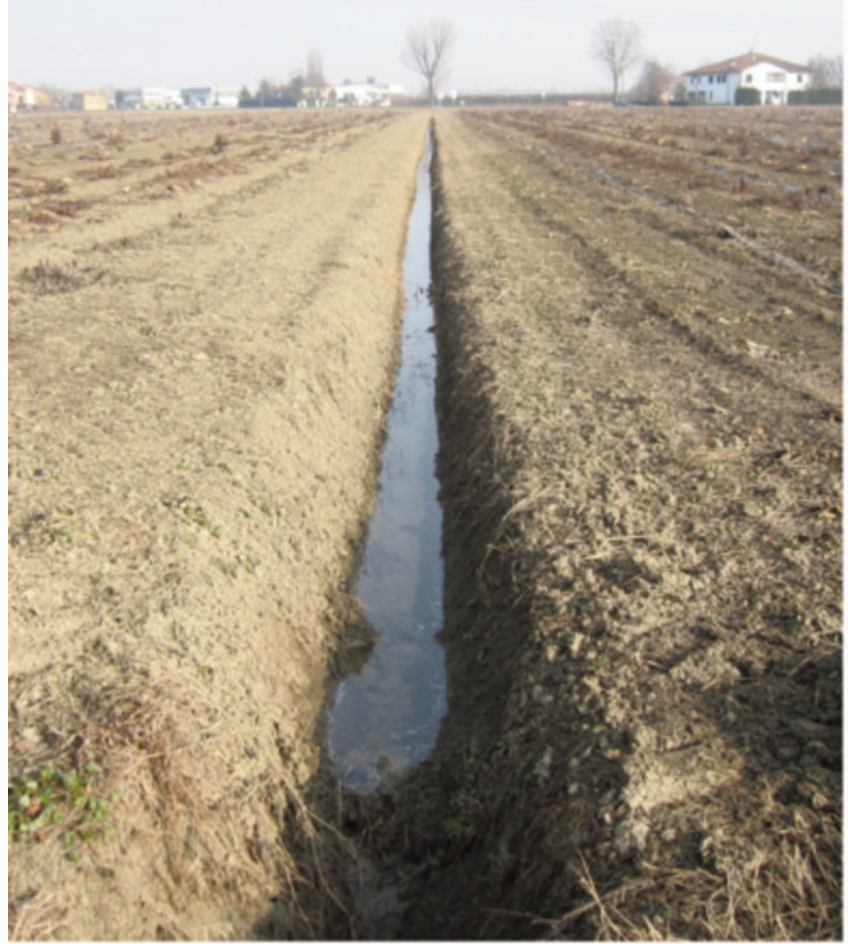

B

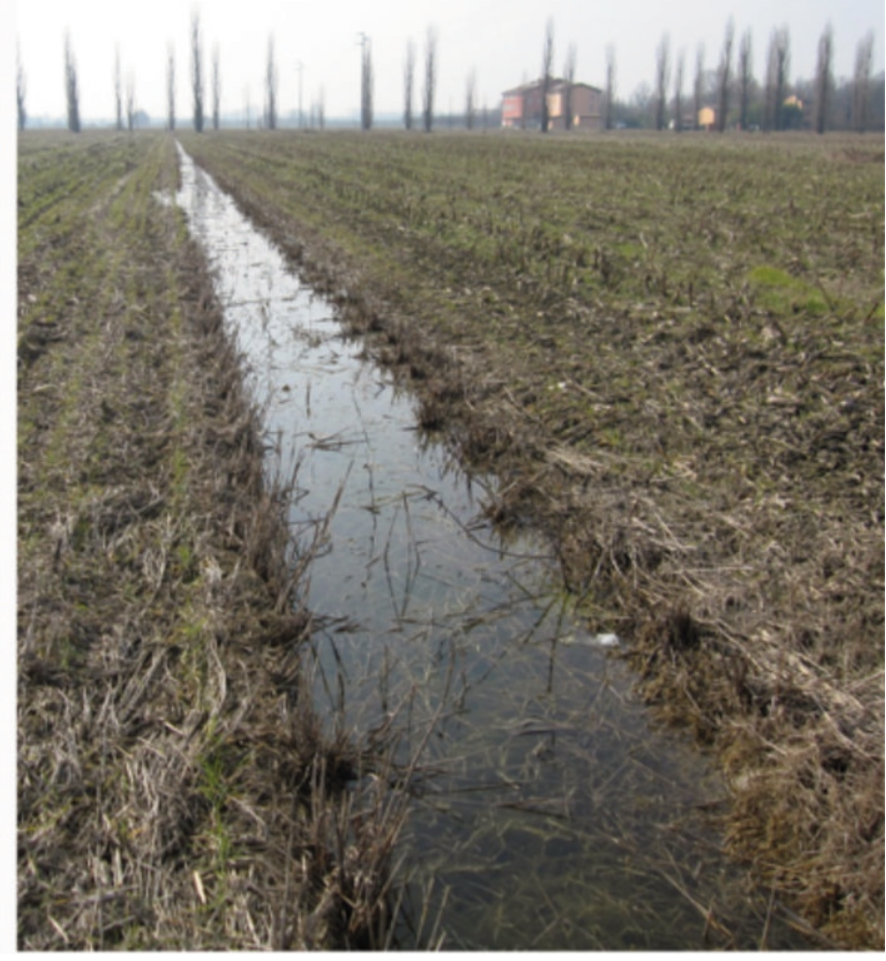

Figure 2. Farm channels in the Po valley; A) example of channel maintained in good condition; B) channel that does not comply with the GAEC standard, as it is invaded by weeds.

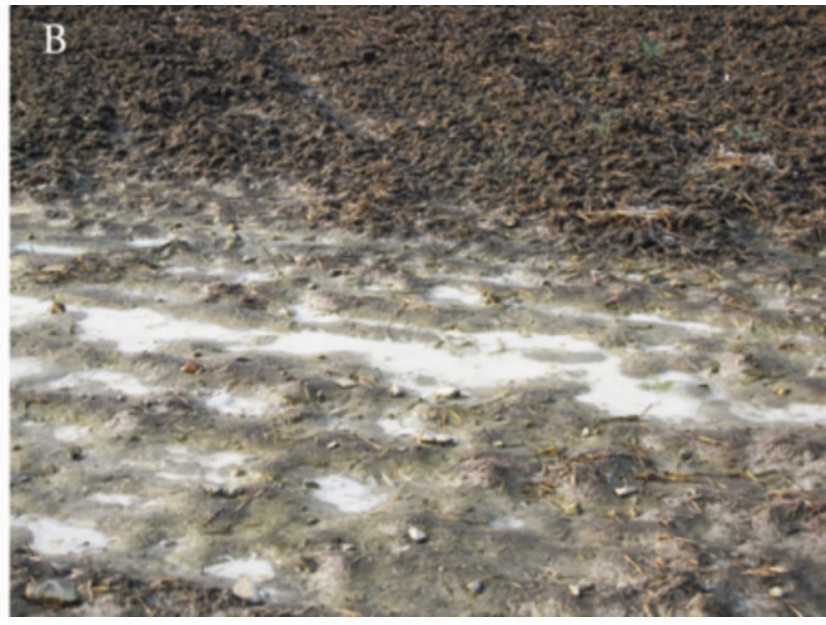

Figure 3. A) Waterlogged arable land (Padova, Veneto); B) destructive effect on structure determined by waterlogging and by freeze/thaw cycles. Note the frozen puddles in the waterlogged area. 


\section{Effects of waterlogging on soil structure, plants and environment}

Soil structure refers to two main components: i) the arrangement of primary soil particles into aggregates, formed by the combination of mineral particles (sand, silt and clay) with organic and inorganic substances through flocculation and cementation processes (Duiker et al., $2003)$; ii) the size, form and continuity and pores. Aggregates are often classified by size: macroaggregates $(>0.25 \mathrm{~mm})$ and microaggregates $(<0.25 \mathrm{~mm})$ (Tisdal and 0ades, 1982). Macroaggregates typically have more organic matter and higher nutrient levels, are less susceptible to erosion, and create larger pores for better water infiltration and aeration than microaggregates (Elliott, 1986; Niewczas and WitkowskaWalczak, 2003; Six et al., 2004). Therefore, a soil with more stable macroaggregates will be of a higher quality than a soil with more stable microaggregates. Degradation of soil structure occurs when aggregates collapse into smaller aggregates or single grains, or particles adhere to one another without any regular definite surface. Soil structure is often expressed in terms of stability of aggregates (Six et al., 2000). This property can be measured through a variety of indexes leading to different results, depending on the goal of the research and on specific aspects of the soil structure under investigation. Moist soil is generally more vulnerable to structural damages caused by mechanical agents. Loss of stability is due to the weakening of the binding agents and to the loss of cohesion between the particles (elementary particles and aggregates) (Marshall et al., 1996). The longer the soil remains in this weakened state, the greater the possibility of damages to the structure. Submersion of the soil can cause the dispersion of siltand-clay aggregates.

Damage to the structure is particularly great with an increase in expandable clay mineral content (Mullins, 2000), salinity and sodicity (Tisdall and Oades, 1982; Churchman et al., 1993; Murray and Grant, 2007), and when the soil is submerged rapidly, thus causing slaking. This phenomenon consists in the rapid breakdown of large soil aggregates $(>2-5 \mathrm{~mm})$ into smaller sized microaggregates $(<0.25 \mathrm{~mm})$. Slaking occurs when aggregates are not strong enough to withstand internal stresses caused by rapid water uptake (Tisdall, 1991; 0ades and Waters, 1991). Internal stresses result from differential swelling of clay particles (Emerson, 1964), trapped and escaping air in soil pores, rapid release of heat during wetting (Collis-George and Lal, 1971), and the mechanical action of moving water (Marshall et al., 1996; Emerson, 1977, 1991). Slaking of loamy soils is mainly due to the pressure of entrapped air, while in clayey soils slaking is influenced by the presence of smectite clays, such as montmorillonite, that shrink when dry and swell when wet (Emerson, 1964).

Moist aggregates slake less readily than air-dry aggregates (Kemper et al., 1975) because they have already completed some or all of their swelling, and some pores are already filled with water.

Soil organic matter promotes aggregate formation and stability of bound aggregates by slowing water uptake by aggregates (Coughlan $e t$ al., 1973). Repeated tillage prevents accumulation or results in loss of organic matter and causes soil aggregates to break down into finer particles. Since loss of organic matter reduces aggregate stability, slaking increases as organic matter decreases (Tisdall and Oades, 1982). The composition of soil organic matter (especially the humified fractions) rather than the total amount per se is responsible for aggregate stabilisation (Hamblin and Greenland, 1977; Dutarte et al., 1993). Organic materials composed predominantly of hydrophobic constituents are more effective and long-lasting than those mainly made of hydrophilic compounds such as in root exudates or polysaccharides of plant tissues (Piccolo and Mbagwu, 1999).

When the soil is submerged, any mechanical disturbance - such as passing farm machines or the flow of water - can cause significant damage to the soil structure. The soil particles broken down through slaking form a dense layer on the soil surface, which clogs pores, reduces infiltration of water and air, and has the potential to impede the emergence of seedlings.

A study conducted in the Midwestern United States revealed that aggregate stability decreased by about $20 \%$ during a 14-day ponding period under reducing conditions from short-term water ponding. Changes in redox sensitive elements, alkaline metals, and dissolved organic carbon under reducing conditions contributed to the decrease in aggregate stability (De-Campos et al., 2009). Some soils are subject to a phenomenon called hardsetting when they are submerged; this means that they collapse very rapidly under their own weight when they subsequently dry out. This causes an increase in apparent density and a strong decrease of porosity. This kind of structural damage extends to a much greater depth than the damage caused by surface crusts (Mulling et al., 1990). After the collapse, the soil may become very hard and hinder both germination and root growth.

A phenomenon similar to hardsetting is coalescence (Or, 1996; Teamrat and Or, 2000; Cockroft and Olsson, 2000), that is the increase of the soil's apparent density (volumic mass) with the increase of the number of wetting/drying cycles (Lanyon et al., 2000). It occurs over a longer period of time and allows the preservation of a larger amount of macropores, meaning that infiltration and drainage are not drastically compromised, while on the other hand root growth may be difficult. There is actually no clear borderline between hardsetting and coalescence, as the speed of the structural collapse depends on a combination of many factors and on the various levels of structural stability found in different soils (Teamrat and Or, 2000; Bresson and Moran, 1995).

Waterlogging a soil instantly sets in motion a series of chemical and microbiological processes that affect nutrient cycling and accumulation of toxins. In addition to retardation of gaseous exchange between soils and air, waterlogging results in changes to microbial populations, a decrease in soil redox potential and an increase in $\mathrm{pH}$. In the absence of $\mathrm{O}_{2}$, anaerobic microorganisms utilise oxidised soil components such as $\mathrm{NO}_{3}{ }^{-}, \mathrm{MnO}_{2}, \mathrm{Fe}(\mathrm{OH})_{2}, \mathrm{SO}_{4}{ }^{2-}$ and dissimilation products of organic matter as electron acceptors in their respiration (Pulford and Tabatabai, 1988). The microbial extraction of oxygen from nitrates and nitrites causes the release of nitrogen and of important greenhouse gases such as methane $\left(\mathrm{CH}_{4}\right)$ and nitrous oxide $\left(\mathrm{N}_{2} \mathrm{O}\right)$.

The damages caused to plants by waterlogging are well known. They are mainly due to a decreased availability of $\mathrm{O}_{2}$ and an accumulation of phytotoxins (Armstrong and Armstrong, 2001). Oxygen deficiency inhibits aerobic respiration, resulting in severe energy deficiency and eventually death (Greenway and Gibbs, 2003). In addition, waterlogging can also reduce the availability of some essential nutrients, such as nitrogen, and increase the availability of nutrients, such as iron (Fe) and manganese (Mn) (Ponnamperuma, 1972). While prolonged waterlogging is detrimental to plants, even short-term transient waterlogging can have long-lasting adverse consequences leading to poor growth and reduced grain yields.

\section{Materials and Methods}

The effects of different durations of waterlogged conditions (total submersion) on structural stability were studied during an original laboratory test carried out in the context of the EFFICOND project on four different soils subject to recurrent waterlogging.

National and international scientific literature does not report any results of similar tests. In fact, most studies were carried out to assess the effects of the quality of the irrigation water on aggregate stability (Murray and Grant, 2007). The most significant study similar to the one presented in this work is the already-cited study by De-Campos et al. (2009) in which three cultivated and three uncultivated soils were 
incubated under anoxic conditions (through the substitution of the atmosphere with argon gas) for $1 \mathrm{~h}$ and for $1,3,7$ and 14 days to determine how changes in the redox status of the soil under a set of controlled temperature and light conditions can impact soil aggregation during short-term flooding conditions.

Two experiments were carried out during this study; the purpose of Test (A) was to identify the disaggregating effect caused by submersion alone for increasing periods, that is the disaggregation due to slaking (which occurs almost instantly as soon as the dry soil is flooded by the water) was assessed together with the disaggregating effect of the duration of submerged conditions. Test (B) made it possible to determine not only the disaggregating effect of submersion for increasing periods of time, but also the effect of the hydrodynamic action of water flowing over the surface when it is drained into the ditches at the end of the waterlogged period.

Both experiments were planned based on a factorial scheme of $4 \times 7$ (with 3 replicates), where the first factor consists of four soils sampled from CRA experimental farms in Vicarello (Province of Pisa), Fagna (Province of Florence), Lodi (Province of Lodi) and Sanluri (Province of Medio Campidano); the second factor consists of 7 durations of waterlogging progressing exponentially: $2.40 \mathrm{~h} ; 1,2,4,8,16$ and 32 days, respectively.

The Vicarello soil derives from Pliocene marine sediments and is classified as Vertic Xerochrept (Soil Survey Staff, 1975); Fagna soil is a Typic Udorthents derived from Pleistocene lacustrine deposits; Lodi soil derives from glacial and fluvio-glacial deposits and is classified as Typic Haplustalf; Sanluri soil is a Typic Fluvaquent derived from fluvio-glacial deposits of Holocene origin.

All the soils are used mainly for cereal production. Samples used for the experiment were taken from fields in good workability conditions (Giardini, 2002).

The main physicochemical characteristics of the soils are shown in Table 1. The table shows that the soils in Vicarello and Fagna are characterised by a higher clay content, while the soils in Lodi and Sanluri are richer in sand, silt (Table 1) and soil rock fragments $>2 \mathrm{~mm}$.

Table 1 summarises the chemical and physicochemical characteristics of the soils examined by the study:

A total of 12 samples were used for Test (A), while Test (B) involved
84 samples. During Test (A), the residual sample after each period of waterlogging was re-used for the next test, which required a longer period of waterlogging. During Test (B), wet sieving was carried out at the end of each submersion period using the single-sieve procedure (De Boodt, 1967; Pagliai et al., 2007).

Each sample consisted of $45 \mathrm{~g}$ of aggregates obtained through dry sieving of soil crumbs that passed through the 9.51-mm sieve and was retained by the $4.76-\mathrm{mm}$ sieve. Each replicate was placed on a sieve with a 2-mm mesh size (keeping the aggregates at a distance from each other in order to avoid interaction). Each sieve was positioned inside an aluminium pan (sized $32 \times 26 \times 5 \mathrm{~cm}$ ) and kept at a distance of $1 \mathrm{~cm}$ from the pan's bottom by placing the edge of the sieve onto three small pedestals. The aggregates were then rapidly submerged by $2 \mathrm{~cm}$ of water, which was added to the bottom of the pan so that wetting of the sample would take place from the bottom via the rise of the water (without creating turbulences and without aiming the water jet directly onto the soil samples).

At the end of each waterlogging period, the material that had passed through the sieve and was deposited in the aluminium pan was assessed for each sample. This amount represents the material that disintegrated through the effect of submersion in water alone (without the addition of further hydrodynamic forces).

Test (A) was carried out as follows: at the end of each waterlogging period, the sieve was removed by lifting it very slowly over a period of 20 seconds (a sufficiently long time to avoid any disaggregating hydrodynamic action). The sieve was then immediately placed into another empty pan. Submerged conditions were then restored through the addition of water (submersion took place over a period of 20 seconds from the moment the water came into contact with the aggregates).

During Test (B), following the submersion period each residual sample was subjected to wet sieving for the determination of structural stability. The sieve with the soil sample was transferred into the automatic wet sieving device and was treated with 30 oscillations per minute for $10 \mathrm{~min}$ and with a $4.5-\mathrm{cm}$ vertical stroke. The device used (designed by the CRA-ABP) electronically controls the duration of the oscillations in order to ensure the exact reproducibility between replicates. At the end of wet sieving, the remaining soil sample on the sieve was dried in the oven at $105^{\circ} \mathrm{C}$ and was then weighed. Finally, the amount of soil

Table 1. Main physicochemical characteristics of soils used for the experiment.

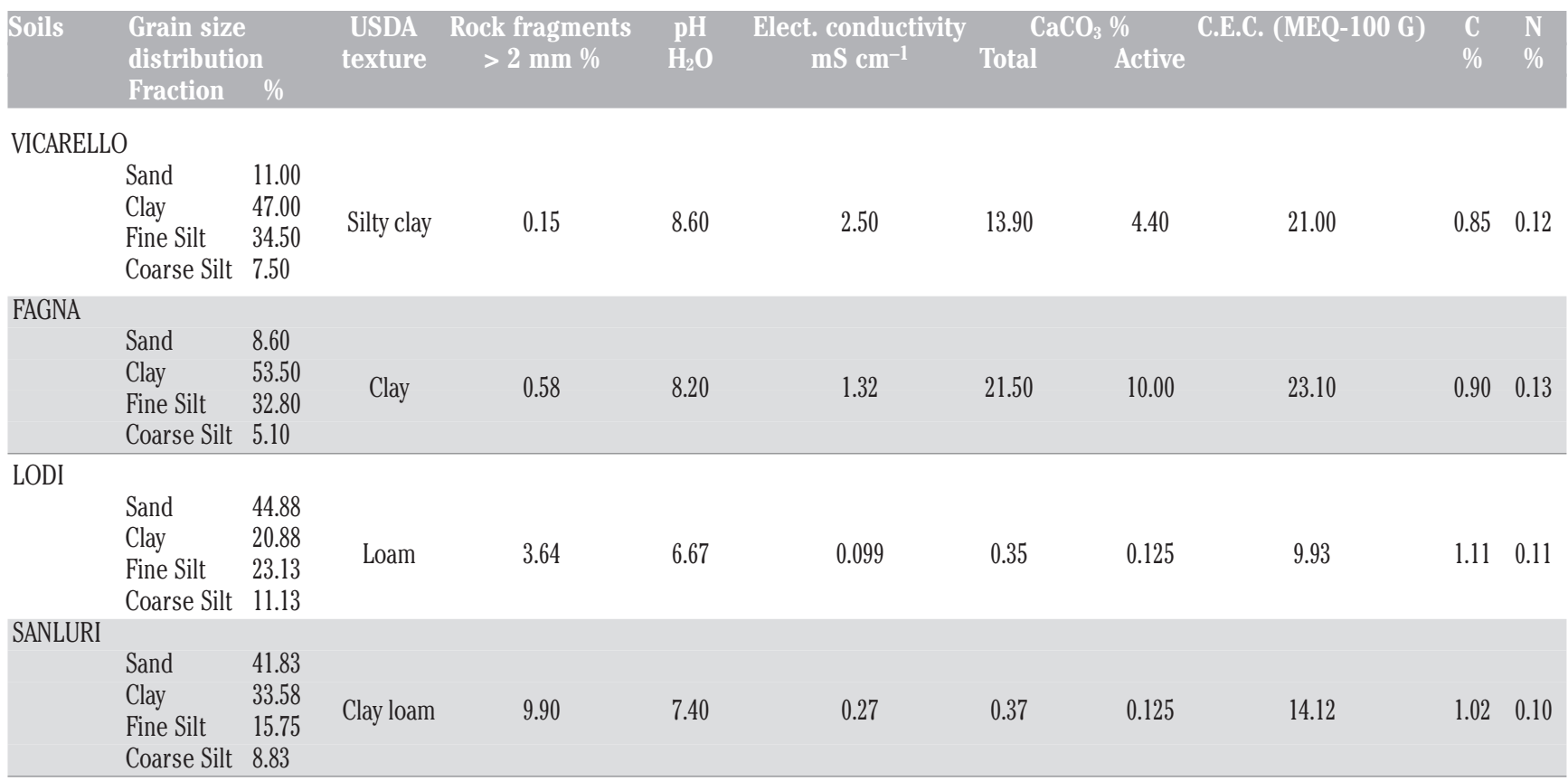


rock fragments $>2 \mathrm{~mm}$ present in the residual fraction was determined. The following parameters were determined for each sample:

- the initial dry weight $\left(\mathrm{P}_{\text {in }}\right)$

- the dry weight of the material that passed through the 2-mm sieve during the waterlogging period $\left(\mathrm{P}_{\text {wat }}\right)$

- the dry weight of the material left on the sieve after wet sieving $\left(\mathrm{P}_{\text {wet }}\right)$

- the dry weight of the rock fragments $>2 \mathrm{~mm}$ in the sample (Pg)

Finally, the following disaggregation indexes were determined:

$$
S L=\left(\frac{P_{w i d}}{P_{i n}-P_{g}}\right) \cdot 100
$$

The SL index represents the percentage of soil lost through disaggregation during the submersion period (net value without the percentage of soil rock fragments $>2 \mathrm{~mm}$ ) both through the effect of slaking at the start of the inundation and through other disaggregating actions that occur during the waterlogging period. The increase of the index corresponds to an increase of the instability. The SL index is also called waterlogging only index.

$$
P_{w s}=\frac{\left(P_{i n}-P_{w e t}-P_{w a t}\right)}{\left(P_{i n}-P_{g}\right)} \cdot 100
$$

The $\mathrm{P}_{\mathrm{ws}}$ index represents the percentage of soil lost solely through the effect of the wet sieving process of the residual sample after the waterlogging period. The increase of the index corresponds to an increase of the instability.

$$
W S I=P_{v i s}+S I
$$

The WSL index expresses the overall percentage of soil disaggregation during submersion and wet sieving. The greater the value of the index, the greater the overall structural instability. The WSL index is also called waterlogging + wet sieving index.

\section{Results of EFFICOND laboratory tests}

The results of the laboratory test are summarised in Figure 4, which shows the percentages (indexes) of disaggregation of the soils obtained with the two tests (A) and (B). The figure shows both the waterlogging-only (SL) indexes and the waterlogging + wet-sieving (WSL) indexes. The results show that treatment (A) always caused less disaggregation than treatment (B). This means that wet sieving (which was meant to simulate the effect of water flowing over the surface during the draining phase) causes an increase in disaggregation.

Considerable differences can be seen in the behaviour of the 4 analysed soil types: the disaggregation percentages of the Vicarello and Fagna samples are considerably and statistically significantly lower than those observed with the Lodi and, above all, Sanluri samples. In fact, the following maximum values were obtained for the WSL index: Vicarello 43.7\%, Fagna 50.9\%, Lodi $76.6 \%$ and Sanluri $99.0 \%$. With respect to Sanluri, the two curves of the WSL and SL indexes meet after a period of 2 days of waterlogging, while this occurs on the fourth day with the Lodi soil. For the Vicarello soil the two curves always remain separated, while the curves of Fagna start meeting after one day of waterlogging. However, the disaggregation of the Fagna soil continues to increase with increasingly long periods of waterlogging, with and without the effect of wet sieving (disaggregation increases less strongly for the WSL index). For the Vicarello soil, waterlogging alone does not lead to very extensive disaggregation (the highest disaggregation
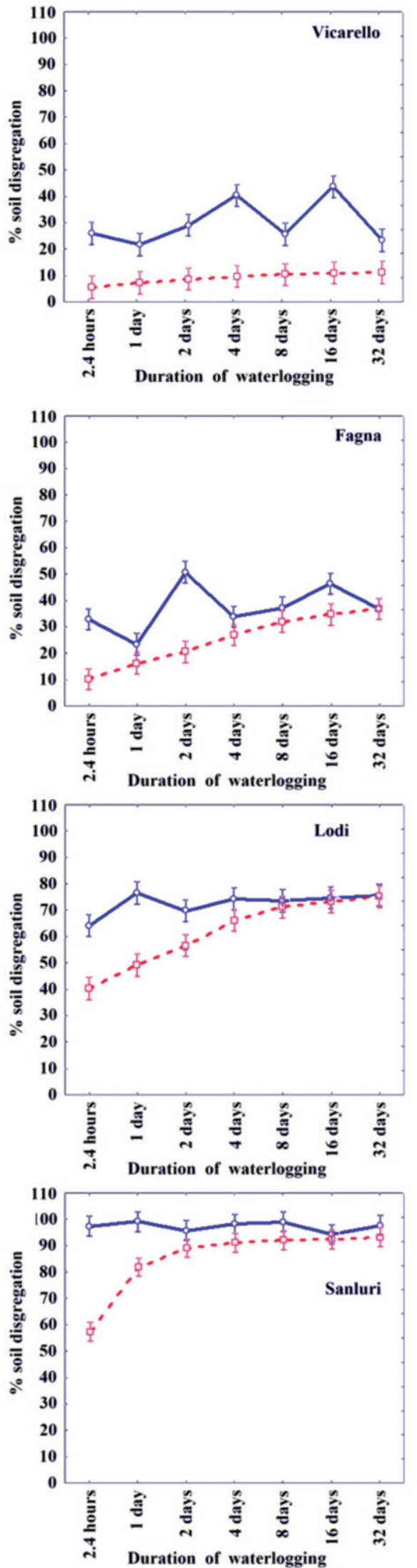

도 Waterlogging + wet sieving ( WSL index )

호 Waterlogging only ( SL index )

Figure 4. Disaggregation percentages of the soils based on the duration of the various waterlogging periods. 
value is $11.14 \%$ after 32 days). Even the added disaggregating effect of wet sieving does not cause very high levels of disaggregation as observed with the other soils (the highest value observed for Vicarello is $43.7 \%$ ). Figure 5 shows the relationships between the disaggregation percentage (WSL index) and some granulometric parameters of the sour soil types. Graph (A) shows that the WSL index decreases with the increase of silt and, even though more weakly, with the increase of clay. Still in Figure 5, Graph (B) shows that the WSL index clearly increases both with the increase of sand + coarse silt and with the increase of the content of rock fragments $>2 \mathrm{~mm} \%$. The analysis of the data concerning the regression equation (Table 2) shows a high statistical significance for the relationship between the increase of the percentage of fine silt and the increase in structural stability (decrease of WSL index). The increase of the percentage of clay also leads to an increase in structural stability (Table 3), even though statistical significance is not achieved. Tables 3 and 4 show a positive correlation between the increase of structural instability and both the increase of the sum of the percentage fractions of sand + coarse silt and the increase of the percentage of rock fragments $>2 \mathrm{~mm}$ contained in the soil (even though levels of statistical significance are not reached). Based on the experiment carried out we can affirm that for the analysed case studies the percentage of soil lost to disaggregation during waterlogging increases with the increase of coarser granulometric fractions. In contrast, disaggregation tends to decrease with the increase of fine and very fine fractions.

\section{Further results of tests carried out in the past and applicable to the assessment of the standard's efficacy}

Effects of soil moisture and of wetting/drying cycles on the stability of microaggregates

Some laboratory experiments carried out in the past by Mbagwu and
Bazzoffi (1988) are useful for the assessment of the standard's efficacy. These tests consisted in: i) assessment of the effects of various levels of soil moisture on the stability of the structure; ii) assessment of the effects of various wetting and drying cycles on the stability of the aggregates.

Three soils with very different characteristics were studies as shown in Table 5. Each replicate consisted of $50 \mathrm{~g}$ of aggregates with a size between 1 and $2 \mathrm{~mm}$. At the end of each treatment, the stability of the microaggregates was determined in accordance with the method described in USDA Manual 60 (1954), which consists in two separate determinations of aggregate size via the pipette method for the clay and silt content, using distilled water with or without Calgon, respectively, as dispersant.

During the first test, the soil samples were kept for 15 days in a balanced state at five different levels of moisture, that is at 0,5, 10,20 and $50 \%$ (weight/weight), respectively.

Subsequently two aggregation indexes were determined: 1) aggregation index of clay and silt (ASC = aggregated silt+clay \%) which provides the assessment of the flocculation level of particles with a diameter $<0.05 \mathrm{~mm}$, and 2 ) aggregation index of clay ( $\mathrm{AC}=$ aggregated clay $\%)$ which provides the assessment of the flocculation level of particles with a diameter $<0.002 \mathrm{~mm}$. In particular for a moisture level of $50 \%$, this test makes it possible to understand if maintaining the farm channel network in efficient working order has a beneficial effect on the soil structure, as good draining of water, ensured by efficient ditches, prevents waterlogging and the dispersion of clay and silt and the consequent formation of crusts.

In the second test, the aggregates were first kept at field capacity for twelve hours and were then subjected to various wetting/drying cycles. The factorial experiment was set up as follows: 3 types of soil $x 6$ hydrological cycles $\mathrm{x} 3$ replicates, with the following hydrological cycles: $\mathrm{C} 1$, $\mathrm{C} 2, \mathrm{C} 3, \mathrm{C} 5, \mathrm{C10}, \mathrm{C} 15$ (the numbers indicate the number of wetting/dry-

Table 2. Summary of regression of the dependent variable WSL (for $3 D$ graphs) $R=0.999$.

\begin{tabular}{lccccccc} 
& B & Std.Evr. B & B & Std.Fir. B & t(1) & P-level \\
Intercept & & & 154.73 & 2.39 & 64.78 & $0.0098^{* *}$ \\
Fine silt \% (x) & -0.98 & 0.034 & -3.52 & 0.12 & -28.98 & $0.022^{*}$ \\
\hline Clay \% (y) & -0.022 & 0.034 & -0.048 & 0.073 & -0.65 & 0.04375 \\
\hline
\end{tabular}

$\mathrm{R}^{2}$ Adj. $=0.998 \mathrm{~F}(2.1)=899.74 \mathrm{P}<0.024$ Standard Error (Std.Err.) estimation=1.819. WSL, waterlogging + wet-sieving index.
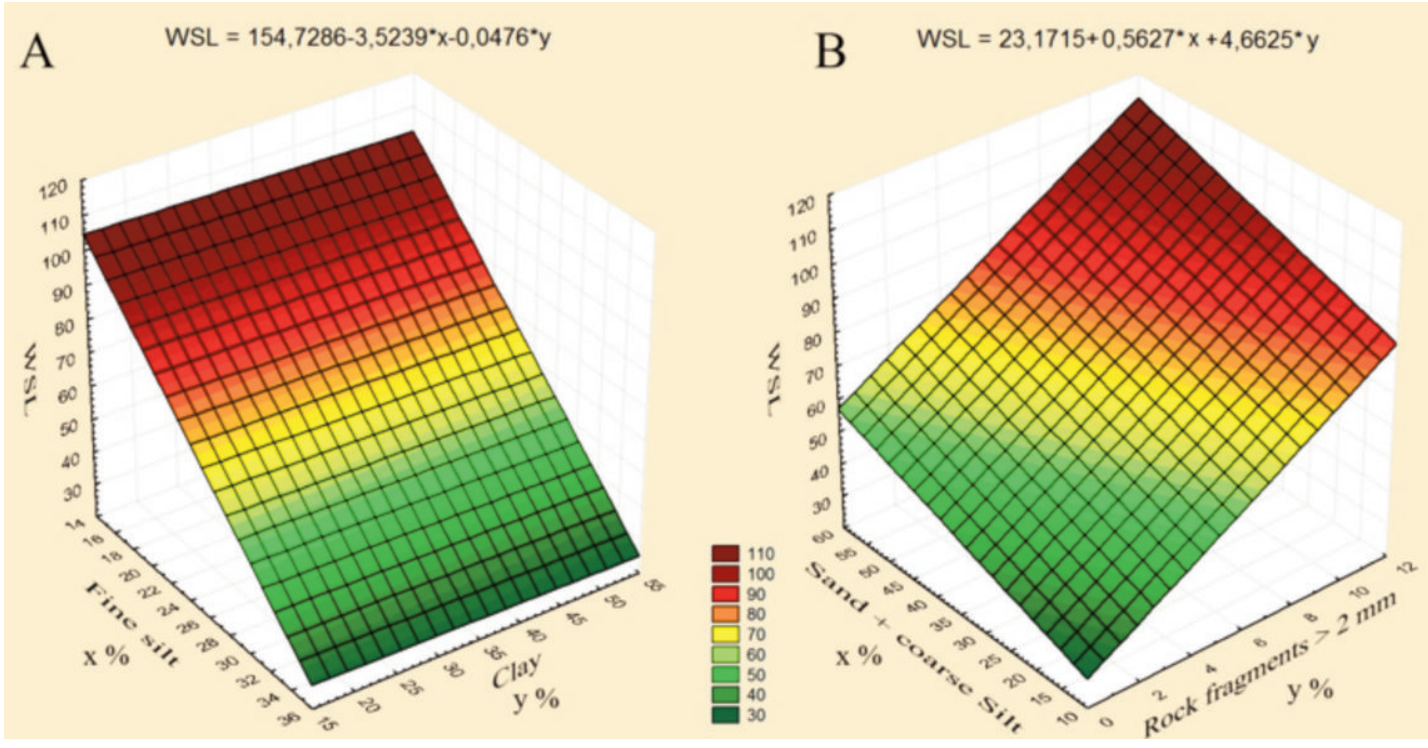
Figure 5. Disaggre- gation percentage (WSL index) in relation to various soil parameters.


ing cycles). In addition to these treatments, two further tests were carried out: i) soil kept dry; and ii) soil kept moist continuously through capillary rise.

The experiment simulates the alternation of waterlogging with periods without waterlogging. This condition may occur on lands without sufficient drainage. Therefore this experiment also makes it possible to assess the environmental effectiveness of the standard.

The results of the test regarding the effects of different levels of soil moisture on structural stability are shown in Table 6 and in Figure 6. The data show a highly significant interaction between the soil type and the moisture level. This means that the soils reacted in very different ways to the initial moisture conditions.

In soils with a sandy loam texture (Lamporecchio soil), the ASC index decreases linearly with the increase of moisture. The highest value for the ASC index was observed when moisture was at the wilting point, while the highest $\mathrm{AC}$ value was observed when the initial moisture was between 5 and 20\%. In loam soils and clay loam soils (Modena and Santa Elisabetta), the highest value for the ASC index was reached with an initial moisture of $10 \%$ and $20 \%$, respectively. The same trend was observed for the AC index.

These results show that in sandy loam soils rapid moisture penetration leads to a disaggregation of silt and clay that increases in direct relation to the increase of moisture in the soil before treatment. By contrast, in soils with a loam and clay loam texture higher initial moisture content leads to a less extensive destruction of the aggregates when these come into rapid contact with water. This condition occurs when the drainage network is not efficient enough to ensure the discharge of the water. As a consequence, waterlogged areas develop where the soil is rapidly and completely submerged.

During the second test, the DS index of the percentage of disaggregation following wetting/drying cycles was determined.

The DS index (De Boodt, 1967) is defined as follows:

$$
D S=\left[\left(M_{1}-M_{2}\right) M_{1}\right] 100
$$

where $M_{l}$ is the initial mass of the soil used for wet sieving and M2 is the mass that remains on the 0.2 -mm sieve after slaking caused by the rapid immersion in distilled water for 20 seconds. The higher the DS index, the lower the stability of the aggregates.

The results show that for all soils the least extensive disaggregation occurred with three wetting/drying cycles. This behaviour was more obvious in soils with a higher silt and clay content. After the third wetting/drying cycle, disaggregation increased with the increase of the

Table 3. Correlation matrix between the disaggregation indexes and the $\%$ of primary particles of soil.

\begin{tabular}{lccccc} 
& $\begin{array}{c}\text { Rock fragments } \\
>2 \mathrm{~mm}\end{array}$ & Sand & Clay & Fine silt & Coarse silt \\
WSL & +0.96 & +0.91 & -0.73 & -1.00 & +0.64 \\
SL & +0.82 & +0.91 & -0.72 & -0.99 & +0.61 \\
\hline
\end{tabular}

number of cycles.

The conditions of the two additional tests (dry soil and permanently saturated soil) did not influence disaggregation in the sandy loam soil of Lamporecchio. By contrast, in the loam soil of Cremona, and even

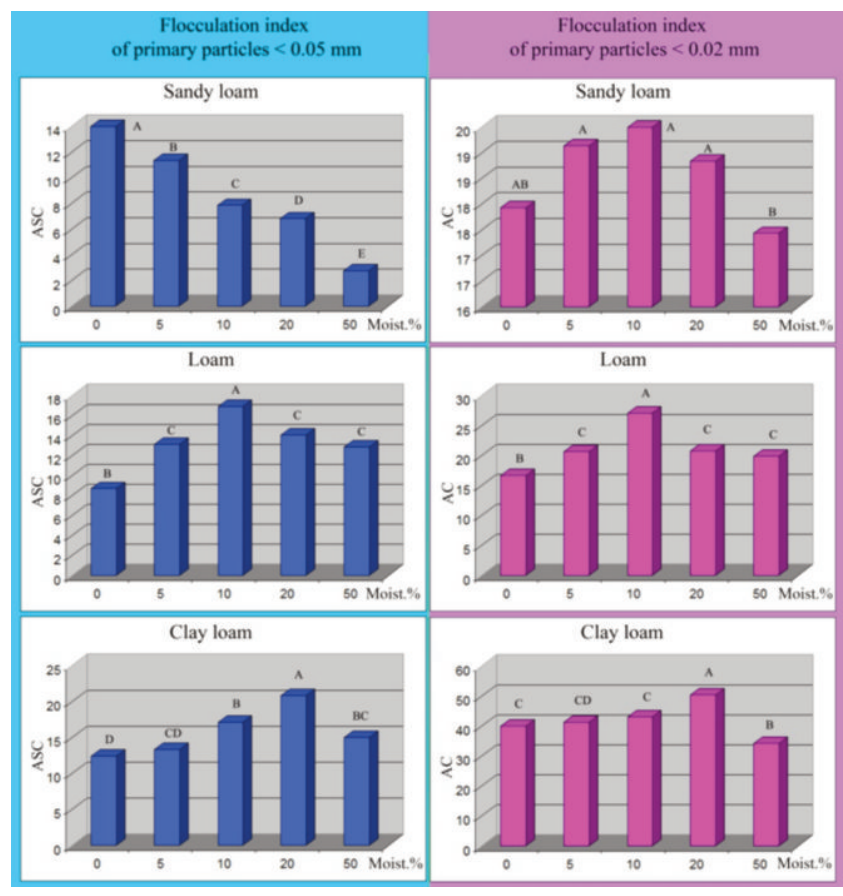

Figure 6. Effects of moisture (\% weight/weight) and soil type on the structural stability of the microaggregates. Recalculated from (Mbagwu e Bazzoffi, 1988). Means with different letters differ significantly $(P \leq 0.005)$.

Table 5. Characteristics of soils used for structural-stability tests (Mbagwu and Bazzoffi, 1988).

\begin{tabular}{lccc}
\multicolumn{1}{c}{ Lamporecchio } & Cremona & Santa Elisabetta & \\
Sand \% & 52.0 & 49.2 & 26.0 \\
Silt \% & 28.3 & 29.9 & 36.6 \\
\hline Clay \% & 19.7 & 20.9 & 37.4 \\
\hline USDA texture & & & \\
classification & Sandy-Loam & Loam & Clay-Loam \\
pH- $\mathrm{H}_{2} \mathrm{O}$ & 5.8 & 6.2 & 7.6 \\
$\mathrm{O} . \mathrm{C} . \%$ & 0.54 & 1.49 & 1.35 \\
\hline $\mathrm{Al}_{2} \mathrm{O}_{3} \%$ & 14.2 & 14.1 & 14.2 \\
$\mathrm{SiO}_{2} \%$ & 55.1 & 66.9 & 69.3 \\
\hline $\mathrm{Moisture} \mathrm{at}_{0.01 \mathrm{MPa}}$ & & & \\
$0.03 \mathrm{MPa}$ & 31.8 & 30.9 & 36.4 \\
$1.50 \mathrm{MPa}$ & 25.0 & 26.1 & 30.4 \\
\hline
\end{tabular}

Table 4. Summary of regression of the variable WSL (waterlogging + wet-sieving index) as a function of coarse silt and of rock fragments $>2 \mathrm{~mm}$ (see Figure 4) $\mathrm{R}=0.994$.

\begin{tabular}{lcccccc} 
& \multicolumn{1}{c}{ B } & Std.Err. B & B & Std.Err. B & t(1) & P-level \\
Intercept & & & 23.17 & 6.46 & 3.59 & 0.17 \\
Course Silt \% (x) & 0.38 & 0.16 & 0.56 & 0.23 & 2.39 & 0.25 \\
\hline
\end{tabular}

$\mathrm{R}^{2}$ Adj $=0.965 \mathrm{~F}(2.1)=43.331 \mathrm{P}<0.10681$ Standard Error (Std.Err.) estimation 5.8098 . 
more so in the clay loam soil of Santa Elisabetta, disaggregation was greater starting with the dry-soil condition. This observation confirms that soils rich in silt and clay are more susceptible to slaking caused by the expansion of smectite clay and that they are therefore also more sensitive to dispersion in case of waterlogging.

The disaggregation data obtained with the wetting/drying cycles were recalculated for this study (Bazzoffi, original data) by establishing the relation of the DS index to the number of cycles and to the percentage of clay+silt.

The following equation was obtained:

$$
D S=a+\frac{b}{x^{2}}+c \cdot y^{3}
$$

where $D S$ is the above-mentioned percentage of disaggregation, $a, b$ and $c$ are the coefficients of equation (5) shown in Table 7, $x$ is the sum of the $\%$ of silt and clay, and $y$ is the number of wetting/drying cycles.

Equation (5), which is shown in graphic form in Figure 7, makes it possible to determine the fragility of the soil structure under the influence to the disaggregating effect of wetting/drying cycles. The graph

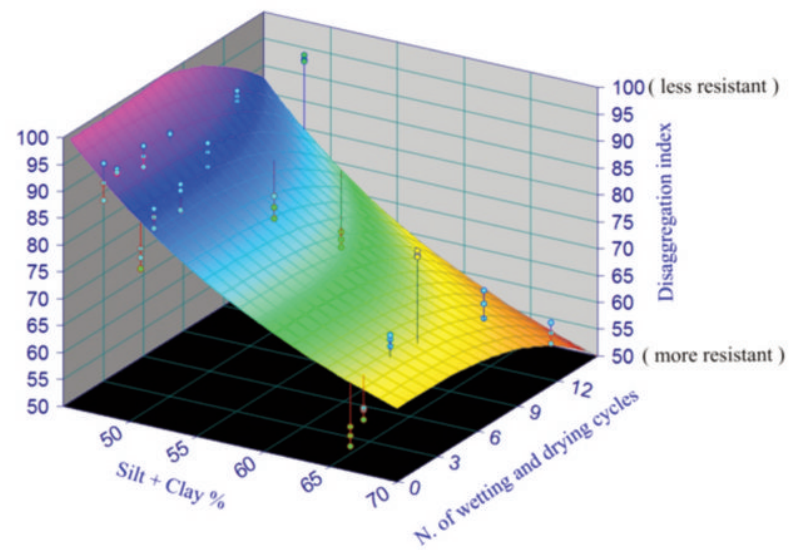

Figure 7. Graphic representation of equation (5) obtained through the recalculation of the data of Mbagwu and Bazzoffi (1998).

Table 6. Analysis of the variance of the effect of moisture and soil type on the structural stability of microaggregates (Mbagwu and Bazzoffi, 1988).

\begin{tabular}{|c|c|c|c|c|c|}
\hline & DF & SS & MS & F & $\mathbf{P}$ \\
\hline \multicolumn{6}{|c|}{ ASC (silt+clay aggregation index) } \\
\hline Soil & 2 & 394.71 & 197.35 & 272.55 & 0.000000 \\
\hline Moisture \% & 4 & 90.38 & 22.59 & 31.20 & 0.000000 \\
\hline Interaction soil x moisture & 8 & 373.13 & 46.64 & 64.41 & 0.000000 \\
\hline Error & 30 & 21.72 & 0.72 & & \\
\hline \multicolumn{6}{|l|}{$A C$ (clay aggregation index) } \\
\hline Soil & 2 & 4880.01 & 2440.00 & 2897.87 & 0.000000 \\
\hline Moisture \% & 4 & 287.28 & 71.82 & 85.30 & 0.000000 \\
\hline Interaction soil x moisture & 8 & 306.57 & 38.32 & 45.51 & 0.000000 \\
\hline Error & 30 & 25.26 & 0.84 & & \\
\hline
\end{tabular}

Table 7. Statistical analysis of equation (5) obtained through the recalculation of the data of Mbagwu and Bazzoffi (1988).

\begin{tabular}{lcccc} 
Equation & Value & $\begin{array}{c}\text { Standard } \\
\text { error }\end{array}$ & t-val. & P ass. $t$ \\
parameter & 37.0078 & 4.2628 & 8.6815 & 0.0000000 \\
a & 130549.02 & 11692.9827 & 11.1647 & 0.0000000 \\
b & -0.0041 & 0.0009 & -4.7892 & 0.0000100 \\
\hline c & & &
\end{tabular}

$\mathrm{R}^{2}=0.74 \quad$ F-value $=73.79$.

Table 8. Effects of the matrix potential on the structural-stability index MWD of aggregates subject to freezing/thawing. Recalculation of data of Mbagwu and Bazzoffi (1989).

\begin{tabular}{|c|c|c|c|c|c|c|}
\hline Soil & Treatment & $\begin{array}{l}\text { W1 } \\
\text { Air dry }\end{array}$ & $\begin{array}{c}\mathrm{W} 2 \\
-1.5 \mathrm{MPa}\end{array}$ & $\begin{array}{c}\text { W3 } \\
-0.033 \mathrm{MPa}\end{array}$ & $\begin{array}{c}\text { W4 } \\
-0.01 \mathrm{MPa}\end{array}$ & $\begin{array}{c}\text { W5 } \\
\text { saturated }\end{array}$ \\
\hline \multicolumn{7}{|l|}{ Modena } \\
\hline & Control & 1.78 & 1.67 & 1.41 & 1.29 & 1.08 \\
\hline & Freeze/thaw & 1.69 & 1.28 & 1 & 0.55 & 0.42 \\
\hline & Matrix potential & 7 & 16 & 24 & 37 & 62 \\
\hline \multicolumn{7}{|l|}{ Santa Elisabetta } \\
\hline & Control & 1.15 & 1.15 & 1.08 & 0.81 & 0.8 \\
\hline & Freeze/thaw & 0.93 & 1.1 & 0.68 & 0.51 & 0.42 \\
\hline & Matrix potential & 2 & 15 & 24 & 35 & 53 \\
\hline \multicolumn{7}{|l|}{ Cremona } \\
\hline & Control & 0.65 & 0.62 & 0.53 & 0.46 & 0.32 \\
\hline & Freeze/thaw & 0.54 & 0.58 & 0.48 & 0.4 & 0.27 \\
\hline & Matrix potential & 1 & 9 & 23 & 30 & 41 \\
\hline
\end{tabular}


clearly shows that the decrease of the clay+silt content leads to a decrease of the microaggregates' stability. Hence these results make it possible to confirm that the observations made during the experiment carried out for aggregates of a size between 4.76 and $9.51 \mathrm{~mm}$ (the above mentioned original experiment) are also valid for microaggregates, that is structural stability decreases as the percentage of sand particles increases.

\section{Effects of soil moisture and freeze/thaw cycles on the stability of} microaggregates

An experiment carried out on three soils by Mbagwu and Bazzoffi (1989) determined the resistance of aggregates after three freeze/thaw cycles under different moisture-content conditions.

This test as well makes it possible to verify the environmental effect of the farm channel network's maintenance on the soil structure.

The characteristics of two soils (Santa Elisabetta and Cremona) are shown in Table 5. The third soil sample used for the experiment was sampled in Modena and has a clay-silt texture (12.2\% sand, $41.4 \%$ silt and $46.4 \%$ clay). The structural stability was determined via the MWD index (Kemper and Chepil, 1965) on aggregates with a size ranging from 4 to $2 \mathrm{~mm}$, using sieves with a mesh size of $2,1,0.5$ and $0.2 \mathrm{~mm}$. The higher the index value, the greater the size of the aggregates and hence the stability of the structure.

The matrix potentials of the soils before the freeze/thaw treatment were as follows: $\mathrm{W} 1=$ air-dry soil, $\mathrm{W} 2=1.5 \mathrm{MPa}, \mathrm{W} 3=0.33 \mathrm{MPa}, \mathrm{W} 4$ $=0.01 \mathrm{MPa}, \mathrm{W} 5=$ saturated soil.

The obtained results are summarised in Table 8 . Figure 8 shows the decrease in percent of the structural-stability index MWD caused by freezing/thawing compared to the untreated control samples.

It can be seen that the disaggregation due to the treatment depends very closely on the matrix potential (and hence on the moisture) of the aggregates before treatment. In general it can be said that a water content between saturation and field capacity predisposes the soils to a much higher level of disaggregation due to freezing compared to air-dry soil or soil at the wilting point.

These results make it possible to deduce that the standard is efficient, as maintaining the drainage channel network in efficient conditions and providing the fields with a convex shape are elements that contribute to the removal of excess water and predispose the soil to the rapid achievement of a water content below the saturation level which,

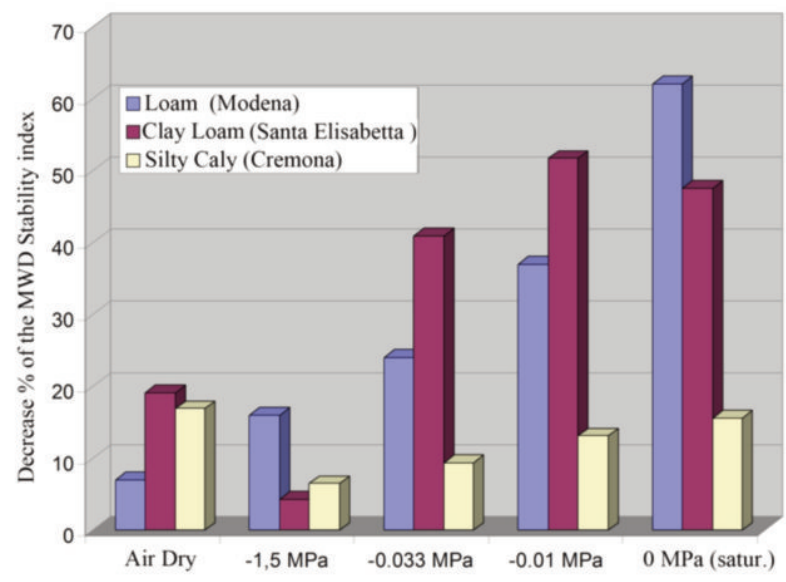

Figure 8. Decrease of the mean weight diameter of aggregates due to freezing/thawing (structural-stability index MWD) compared to untreated control samples (Air dry) based on the water content at the different matrix potentials. Recalculation of data from Mbagwu and Bazzoffi (1989).d through the recalculation of the data of Mbagwu and Bazzoffi (1998). as has been shown above, makes the soil structure susceptible to damages caused by freezing/thawing. A previous experiment carried out with the same soils sampled in Cremona, Santa Elisabetta and Modena examined the effects of a growing number of freeze/thaw cycles $(0,1$, $3,5,11$ cycles) on aggregates with a size ranging from 10 to $4 \mathrm{~mm}$ following slow wetting (by capillary rise) to field capacity (Bazzoffi and Mbagwu, 1986). A logarithmic degradation of structural stability in relation to the number of freeze/thaw cycles was observed for the three soils; however, most of the disaggregation occurred after three cycles. Compared to the control samples not subjected to freezing/thawing, after three cycles the class of aggregates $>2 \mathrm{~mm}$ decreased by $18 \%$ in the soil from Modena, by $91 \%$ in the soil from Santa Elisabetta and by $84 \%$ in the soil from Cremona.

This experiment shows that only a few freeze/thaw cycles are necessary to cause a significant structural degradation of soils with high water content and with texture ranging from loamy to clayey.

\section{Conclusions}

The experiments have confirmed that maintaining the farm channel networks and giving fields a convex shape has a positive effect in terms of predisposing the soil to ideal conditions for the preservation of the structure. In fact, these measures reduce the probability of the occurrence of waterlogged conditions.

The Standard was assessed only with respect to its effect on soil structure, without taking into consideration that the removal of excess water also leads to a series of advantages for soil microflora, seed germination, plant growth and the atmosphere.

To combat waterlogging phenomena it is necessary to avoid the formation of a plough pan, which is a compacted layer created by the ploughshare while cutting the soil. Subsoil layers may also become compacted through the use of rotary devices during tillage. Such compact layers disrupt pore connectivity and thus drastically reduce drainage.

For this reason it is suggested that the Standard should be amended through the addition of a compulsory disposition that obliges farmers to adopt alternative tillage systems in place of traditional ploughing in areas subject to repeated waterlogging; such systems include chisel ploughing carried out with chisel elements or subsoilers (mole ploughers) that operate at various depths with passages in a single direction or crosswise and are able to break up the ground without altering or compacting the subsoil horizons.

Another system that can prevent the formation of a plough pan is chisel ploughing in combination with superficial ploughing. A deep subsoiler is used in combination with a superficial plough to achieve the so-called two-layer tillage. This type of operation combines the benefits of superficial ploughing with those of deep chisel ploughing. In addition to advantages with respect to expenses and energy consumption, two-layer tillage does not lead to the formation of a plough pan and benefits the humification of organic substances and crop residues.

The standard should also limit rotary tillage, as this causes the partial pulverisation of the soil, which can easily become compacted again and thus form a surface crust after rainfall of even moderate intensity, especially on soils with significant silt content.

\section{References}

Armstrong J., Armstrong W., 2001. An overview of the effects of phytotoxins on Phragmites australis inrelation to die-back. Aquat. Botany 69:251-268. 
Bazzoffi P., Mbagwu J.S.C., 1986. Modification of transient soil physical properties by frost action. Effects of different cycles of freezing and thawing. Annali Istituto Sperimentale per lo Studio e la Difesa del Suolo 17:57-66.

Bresson L., Moran C.J., 1995. Structural change induced by wetting and drying in seedbeds of a hardsetting soil with contrasting aggregate size distribution. Eur. J. Soil Sci. 46:205-214.

Cockroft B., Olsson K.A., 2000. Degradation of soil structure due to coalescence of aggregates in no-till, no-traffic beds in irrigated crops. Aust. J. Soil Res. 38:61-70.

Churchman G.J., Skjemstad, J.O., Oades J.M., 1993. Influence of clay minerals and organic matter on effects of sodicity on soils. Aust. J. Soil Res. 31:779-800.

Collis-George N., Lal R., 1971. Infiltration and structural changes as influenced by initial moisture content. Aust. J. Soil Res. 9:107-116.

Coughlan K.J., Fox W.E., Hughes J.D., 1973. A study of the mechanisms of aggregation in a krasnozem soil. Aust. J. Soil Res. 11:65-73.

De Boodt M., 1967. West European Methods of Soil Structure Determinations. Int. Soc. Soil. Sci. Communication I, West Europe Group, Part VI, pp 17-18; 36-38.

De-Campos A.B., Mamedov A.I., Huang C., 2009. Short-Term Reducing Conditions Decrease Soil Aggregation. Soil Sci. Soc. Am. J. 73:550559.

Duiker S.W., Rhoton F.E., Torrent J., Smeck N.E., Lal R., 2003. Iron (hydr)oxide crystallinity effects on soil aggregation. Soil Sci. Soc. Am. J. 67:606-611.

Dutarte P., Batoli F., Andreux F., Portal J.M., Ange A., 1993. Influence of content and nature of organic matter on the structure of some sandy soils from West African. Geoderma 56:459-478.

Elliott E.T., 1986. Aggregate structure and carbon, nitrogen, and phosphorus in native and cultivated soils. Soil Sci. Soc. Am. J., 50:627633.

Emerson W.W., 1964. The slaking of soil crumbs as influenced by clay mineral composition. Aust. J. Soil Res. 2:211-217.

Emerson W.W., 1977. Physical properties and structure. In: J.S. Russell and E.L. Greacen (eds.) Soil factors in crop production in a semiarid environment. University of Queensland Press, St. Lucia, Qld, Australia, pp 78-104.

Emerson W.W., 1991. Structural decline of soils, assessment and prevention. Aust. J. Soil Res. 29:905-921.

Giardini L., 2002. Agronomia generale ambientale e aziendale, $5^{\circ}$ ed. Patron Editore, Bologna, Italy.

Greenway H., Gibbs J., 2003. Mechanisms of anoxia tolerance in plants. II. Energy requirements for maintenance and energy distribution to essential processes. Funct. Plant Biol. 30:999-1036.

Kemper W.D., Chepil W.S., 1965. Size distribution of aggregates. In: C.A. Black (ed.) Methods of Soil Analysis. Part 1, 1st ed. Am. Soc. of Agronomy Ed., Madison, WI, USA, pp 499-510.

Kemper W.D., Olsen J.S., Hodgdon A., 1975. Irrigation methods as a determinant of large pore persistence and crust strength of cultivated soils. Soil Sci. Soc. America Proc. 39:519-523.

Hamblin A.P., Greenland D.J., 1977. Effect of organic constituents and complexing metal ions on aggregate stability of some. East Anglian soils. J. Soil Sci. 31:203-215.

Landi R., 2004. Sistemazioni idraulico-agrarie. In: Atlante dei tipi geografici. IGM ed., Firenze, Italy, pp 407-409.

Lanyon, D., Cass. A., Olsson, K.A. and Cockroft, B. 2000. The dynamics of soil physical properties in a water stable soil: the effect of irriga- tion rate, aggregate size distribution and overburden pressure. pp 415-422 in Proc. 4th Int. Conf. on Soil Dynamics, Adelaide, Asutralia.

Marshall T.J., Holmes J.W., Rose C.W., 1996. Soil Physics 3rd edition. Cambridge University Press.

Mbagwu J.S.C., Bazzoffi P., 1988. Stability of microaggregates as influenced by antecedent moisture content, organic waste amendment and wetting and drying cycles. Catena 15:565-576.

Mbagwu J.S.C., Bazzoffi P., 1989. Effect of antecedent matric potential on the stability of soil aggregates subjected to cyclic freezing and thawing as evaluated by three structural indices. Soil Technol. 2:59-70.

Mullins C.E., 2000. Hardsetting soils. In: M.E. Sumner (ed.) Handbook of Soil Science. CRC Press, Boca Raton, FL, USA, pp G70-87.

Mullins C.E., Macleod D.A., Northcote K.H., Tisdall J.M., Young I.M., 1990. Hardsetting soils: behaviour, occurrence and management. Adv. Soil Sci. 11:37-108.

Murray R.S., Grant C.D., 2007. The Impact of Irrigation on Soil Structure. The National Program for Sustainable Irrigation (Land \& Water Australia) Publ., Braddon, Australia.

Niewczas J., Witkowska-Walczak B., 2003. Index of soil aggregate stability as linear function value of transition matrix elements. Soil Till. Res. 70:121-130.

Oades J.M., Waters A.G., 1991. Aggregate hierarchy in soils. Aust. J. Soil Res. 29:815-828.

Or D., 1996. Wetting-induced soil structural changes: The theory of liquid phase sintering. Water Resour. Res. 32:3041-3049.

Pagliai M., 2007. Metodi di analisi fisica del suolo. Coordinatore Marcello Pagliai, Collana di Metodi Analitici per l'Agricoltura diretta da Paolo Sequi. Capitolo V. Stabilità e distribuzione dimensionali degli aggregati. Franco Angeli ed., Milano, Italy.

Piccolo A., Mbagwu, J.S.C., 1999. Role of hydrophobic components of soil organic matter in soil aggregate stability. Soil Sci. Soc. Am. J. 63:1801-1810.

Ponnamperuma F.N., 1972. The chemistry of submerged soils. Adv. Agron. 24:29-96.

Pulford I.D., Tabatabai M.A., 1988. Effect of waterlogging on enzyme activities in soils. Soil Biol.Biochem. 20:215-219.

Six J., Bossuyt H., Degryze,S., Denef K., 2004. A history of research on the link between (micro)aggregates, soil biota, and soil organic matter dynamics. Soil Till. Res. 79:7-31.

Six J., Elliott E.T., Paustian K., 2000. Soil structure and soil organic matter: II. A normalized stability index and the effect of mineralogy. Soil Sci. Soc. Am. J. 64:1042-1049.

Soil Survey Staff, 1975. Soil taxonomy: a basic system of soil classification for making and interpreting soil surveys. USDA Soil Conservation Services, Agriculture Handbook No. 436, Government Printing Office, Washington, DC, USA.

Teamrat A.G., Or D., 2000. Dynamics of soil aggregate coalescence governed by capillary and rheological processes. Water Resour. Res. 36:367-379.

Tisdall J.M., 1991. Fungal hyphae and structural stability of soil. Aust. J. Soil Res. 29:729-743.

Tisdall J.M., Oades J.M., 1982. Organic matter and water-stable aggregates in soils. J. Soil Sci. 33:141-163.

USDA, 1954. Diagnosis and improvement of saline and alkali soils. Agriculture Handbook N. 60, United States Salinity Laboratory, Riverside, CA, USA. 